\title{
Theoretical Analysis of the Relationship between Technological Innovation and Intellectual Property Protection
}

\author{
Jiahui Feng \\ Baoshan Campus of Shanghai University in China \\ jetfeng1993@163.com
}

\begin{abstract}
Keywords: Intellectual property protection; Technological innovation; Sub-game refinement Nash equilibrium; Cournot competition model
\end{abstract}

\begin{abstract}
Based on the theoretical perspective, this paper examines the relationship between intellectual property protection and technological innovation in developing countries or regions. Based on the technology spillover under closed economy, this paper constructs a Cournot competition model based on sub-game refined Nash equilibrium, and analyzes the relationship between intellectual property protection and technological innovation. In the process of solving the use of reverse induction method, first consider the second phase of the Cournot yield competition, and then consider the first stage of the game. The theoretical analysis shows that when the level of intellectual property protection in developing countries is higher than a certain threshold, the level of technological innovation decreases with the strengthening of intellectual property protection. When the level of intellectual property protection is lower than a certain threshold, The level of technological innovation will increase with the strengthening of intellectual property protection.
\end{abstract}

\section{Introduction}

As an important institutional arrangement to encourage the production of new knowledge, the impact of intellectual property protection policies on technological innovation and economic growth in a country or region has received increasing attention. However, unlike the high level of consensus on strengthening intellectual property protection in favor of technological innovation in developed countries, it is still a controversial issue to strengthen the protection of intellectual property rights that can promote the innovation capacity of developing countries. To a certain extent plagued the development of intellectual property policies in developing countries.

So, what is the effect of intellectual property protection on China's innovation capacity? The impact of different effects in the level of innovation there are differences, in particular, intellectual property rights on China's strong technical capacity of the promotion of what will happen? Behind this, intellectual property protection is through what kind of impact channels and mechanism of action on China's technological innovation have a role? This paper uses the two-stage game model to analyze the above problems one by one to comprehensively understand the relationship between intellectual property protection and China's innovation ability.

\section{Literature Review}

In the study of developed countries, the vast majority of studies show that strengthening intellectual property protection is conducive to the promotion of innovation (Fu and Yang, 2009)[1]. Arrow (1962) [2]regarded innovation as the study of the production of knowledge, for the later scholars concerned about the creation and diffusion of knowledge and its relationship with social welfare, intellectual property as a way of resource allocation theory laid the foundation.

In the theoretical research, scholars based on Helpman (1993)[3] based on the North innovation, the South imitation of the North-South framework of the technological progress model, that the strengthening of intellectual property protection will inhibit the imitation of the South countries, worsening the terms of trade in the South Not only will inhibit the technological progress of the southern countries, but also will lead to the slowdown in global innovation. However, Lai (1998) [4] and other 
scholars pointed out that the technology diffusion in developed countries is an important way for developing countries to enhance their ability to innovate. Strengthening the protection of intellectual property rights in the countries of the South can bring greater attraction to the entry of transnational corporations so that their enterprises can More benefit from the international technology spillovers, and then to the country's technological innovation to promote the role.

In the empirical study, Krammer (2009)[5] based on the empirical analysis of 16 Eastern European countries, found that intellectual property protection has a significant positive impact on the innovation capacity of Eastern European countries. Lo (2011)[6] analyzed the reform of the patent system in China in 1986 and found that the strengthening of intellectual property protection after the implementation of the reform not only increased the foreign direct investment, but also promoted the increase of R\&D investment of local enterprises, Trademark Office (USPTO) Increased number of patents. However, Kim (2012)[7] have shown that the impact of intellectual property protection on technological innovation in developing countries is not significant. Schneide (2005)[8] based on 1970 to 1990, 47 countries, empirical analysis found that strengthening the protection of intellectual property rights in developed countries has a significant ability to innovate Promote the role, but the technical innovation in developing countries have a negative impact. Allred and Park (2007)[9] also show that strengthening intellectual property protection has a negative impact on the patent application activities of developing countries as a whole. In addition, there are some studies that show that the impact of intellectual property protection on technological innovation in developing countries is non-linear.

As with cross-country research based on developing countries, the current empirical conclusions on the relationship between intellectual property protection and China's innovation and technological progress are not the same. In the literature of "Suppression", Hu and Mathews (2008)[10] used the timing data from 1991 to 2005 to find that intellectual property protection has a significant negative impact on China's innovation capacity.

In view of the great controversy existing in the existing research, this paper constructs a simple Cournot competition model based on the perspective of technology spillover under closed economy to analyze the relationship between intellectual property protection and technological innovation.

\section{Theoretical Analysis}

Basic Model Settings. Assuming that there are two competing firms 1 and 2 in the country, they produce a product 1 and product 2, respectively, and there are horizontal differences and vertical differences between the two products. Horizontal difference refers to a concept of the size of the two products, when the level of the two products when the difference is large, that they are completely independent of each other; when the difference between the two products is small and the quality is exactly the same, Call them completely replace. The level difference between the two products is used $\sigma$ to represent, and the level of the product is assumed to be exogenous given. Vertical difference refers to the quality difference between the two products, usually considered the technical level of advanced enterprises than the technical level of backward enterprises have a higher product quality. Assuming the degree of vertical difference between the two products endogenous decision, which depends on the size of the enterprise $R \& D$ investment, generally believed that the greater the $R \& D$ investment enterprises, the higher the quality of their products.

Assuming that there is an intellectual property protection in the country and that the protection of intellectual property is incomplete, it means that there is a technology spillover effect in the innovation of the enterprise, which is more realistic for developing countries. Assuming that both firm 1 and firm 2 are engaged in $R \& D$ inputs engaged in technological innovation activities, the purpose of $R \& D$ inputs is to improve the quality of their products so that their products can gain more consumers in the market, Favorable position. Assuming the R\&D investment of firm 1 is $R_{1}$, the R\&D investment of firm 2 is $R_{2}$. The incompleteness of intellectual property protection determines the new technology generated by R\&D investment of enterprise 1 and enterprise 2 to produce technical spillover effect.

Assuming that the intensity of intellectual property protection in this country is $\theta, \theta$ is greater, the greater the intensity of technology spillovers, that is, the intensity of intellectual property protection is 
inversely related to the intensity of technology spillovers, so we can set $1-\theta$ is the intensity of technology spillovers, that is, the knowledge of a country The higher the level of property protection, the smaller the technology spillovers in the country, the harder it is for other firms to get the technology spillovers from innovative firms, and vice versa.

We can represent the quality of the products obtained by Enterprise 1 and Enterprise 2 as a function of the R\&D inputs and intellectual property protection strengths of both firms:

$$
\begin{aligned}
& u_{1}=\lambda R_{1}^{1 / 4}+\lambda(1-\theta) R_{2}^{1 / 4} \\
& u_{2}=\lambda(1-\theta) R_{1}^{1 / 4}+\lambda R_{2}^{1 / 4}
\end{aligned}
$$

Assuming that the country has a total of $\mathrm{N}$ consumers of the same preference, they also consume both products produced by Enterprise 1 and Enterprise 2. Since it is assumed that there is a horizontal difference between the two products and there are vertical differences between the two products, we use the following representative function of the representative consumer form:

$$
U=q_{1}+q_{2}-\left(\frac{q_{1}}{u_{1}}\right)^{2}-\left(\frac{q_{2}}{u_{2}}\right)^{2}-\sigma \frac{q_{1}}{u_{1}} \frac{q_{2}}{u_{2}}+M
$$

The budget constraint for representative consumers is:

$$
Y=p_{1} q_{1}+p_{2} q_{2}+M
$$

To solve the above extreme problem, we can get the demand function of each consumer to product 1 and product 2 as follows:

$$
\begin{aligned}
& p_{1}=1-\frac{2 q_{1}}{u_{1}^{2}}-\frac{\sigma}{u_{A}} \frac{q_{2}}{u_{2}} \\
& p_{2}=1-\frac{2 q_{2}}{u_{2}^{2}}-\frac{\sigma}{u_{2}} \frac{q_{1}}{u_{1}}
\end{aligned}
$$

Model Analysis. Assume that firm 1 and firm 2 carry out a two-stage non-cooperative game. In the first stage, it is assumed that the optimal level of quality is chosen so that the net profit is maximized under the condition that the other party has made a selection of quality levels. In the second stage, it is assumed that the two firms carry out Cournot production competition under the condition that the two enterprises have determined their optimal quality level, that is, under the condition that the opponent has chosen the output, the optimal output of each of them is maximized The In order to find the sub-game Nash equilibrium solution of the two-stage game, we use the reverse induction method, that is, the second stage of the Cournot yield competition, and then consider the first stage of the game.

The second stage, enterprise 1 and enterprise 2 each choose their own optimal level of production, so that their own production profits and reach the maximum. Assuming that the marginal production costs of firm 1 and firm 2 are both $c$, and because there are $\mathrm{N}$ consumers with the same preference on the market, the sales volume of firm 1 and firm 2 is $N q_{1}$ and $N q_{2}$, combined with Eq.5 and Eq.6 The profit function of firm 1 and enterprise 2 is obtained as follows:

$$
\begin{aligned}
& \pi_{1}=N\left(p_{1}-c\right) q_{1}=N\left(1-\frac{2 q_{1}}{u_{1}^{2}}-\frac{\sigma}{u_{1}} \frac{q_{2}}{u_{2}}-c\right) q_{1} \\
& \pi_{2}=N\left(p_{2}-c\right) q_{2}=N\left(1-\frac{2 q_{2}}{u_{2}^{2}}-\frac{\sigma}{u_{2}} \frac{q_{1}}{u_{1}}-c\right) q_{2}
\end{aligned}
$$

In the Cournot yield competition conditions, according to the profit of the first-order conditions can be obtained from the two enterprises the optimal output were:

$$
\begin{aligned}
& q_{1}^{*}=\frac{(1-c) u_{1}\left(4 u_{1}-\sigma u_{2}\right)}{(4-\sigma)(4+\sigma)} \\
& q_{2}^{*}=\frac{(1-c) u_{2}\left(4 u_{2}-\sigma u_{1}\right)}{(4-\sigma)(4+\sigma)}
\end{aligned}
$$

Now analyze the first stage of the game. In the first stage, firm 1 and firm 2 choose their respective optimal quality levels to maximize their own net profit. By comparing their respective net profit functions, First-order derivative, the first-order condition that maximizes net profit: 


$$
\begin{aligned}
& \frac{d \pi_{1}^{*}}{d R_{1}}=\frac{\partial \pi_{1}^{*}}{\partial u_{1}} \frac{\partial u_{1}}{\partial R_{1}}+\frac{\partial \pi_{1}^{*}}{\partial u_{2}} \frac{\partial u_{2}}{\partial R_{1}}=1 \\
& \frac{d \pi_{2}^{*}}{d R_{2}}=\frac{\partial \pi_{2}^{*}}{\partial u_{2}} \frac{\partial u_{2}}{\partial R_{2}}+\frac{\partial \pi_{2}^{*}}{\partial u_{1}} \frac{\partial u_{1}}{\partial R_{2}}=1
\end{aligned}
$$

As the two companies are in a symmetrical position, according to Eq.1 and Eq.2, we get the optimal quality level of the two firms when the game is balanced,

$$
u_{1}^{*}=u_{2}^{*}=\lambda(2-\theta) R_{c}^{1 / 4}
$$

Which $R_{c}$ represents the two firms in the equilibrium state of the same optimal R\&D input level. level:

Eq.7, Eq.8 were brought into Eq.11 and Eq.12, can be obtained two products of the best quality

$$
\begin{aligned}
& u_{1}^{*}=u_{2}^{*}=\frac{N^{1 / 2}(1-c) \lambda^{2}[4-(1-\theta) \sigma]^{1 / 2}(2-\theta)^{3 / 2}}{(4-\sigma)^{1 / 2}(4+\sigma)} \\
& R_{c}=\frac{N^{2}(1-c)^{4} \lambda^{4}[4-(1-\theta) \sigma]^{2}(2-\theta)^{2}}{(4-\sigma)^{2}(4+\sigma)^{4}}
\end{aligned}
$$

Because the optimal R\&D level of the firm determines the optimal quality of the product produced by the firm, we can use it to represent the level of technological innovation in a country. We can see the level of intellectual property protection as a policy variable that can be controlled by the government. In order to maximize the optimal R\&D investment level of the two companies, the level of technological innovation in the country is maximized, we should let $\partial R_{c} / \partial \theta=0$. The optimal level of intellectual property protection is:

$$
\theta^{*}=\frac{3 \sigma-4}{2 \sigma}, \sigma \in\left(\frac{4}{3}, 2\right)
$$

Thus, when a country's level of intellectual property protection is above a certain threshold, raising the level of intellectual property protection in the country will reduce the level of technological innovation in the country; when a country's level of intellectual property protection is below a certain threshold, To improve the level of intellectual property protection in the country, can improve the level of technological innovation in the country. In order to make a country's technological innovation ability to achieve the best, there is a moderate level of intellectual property protection. Through the above analysis, we find that under the condition of the difference of the product level, a country's technological innovation level and intellectual property protection efforts to show an "inverted U-type" relationship (shown in Fig. 1).

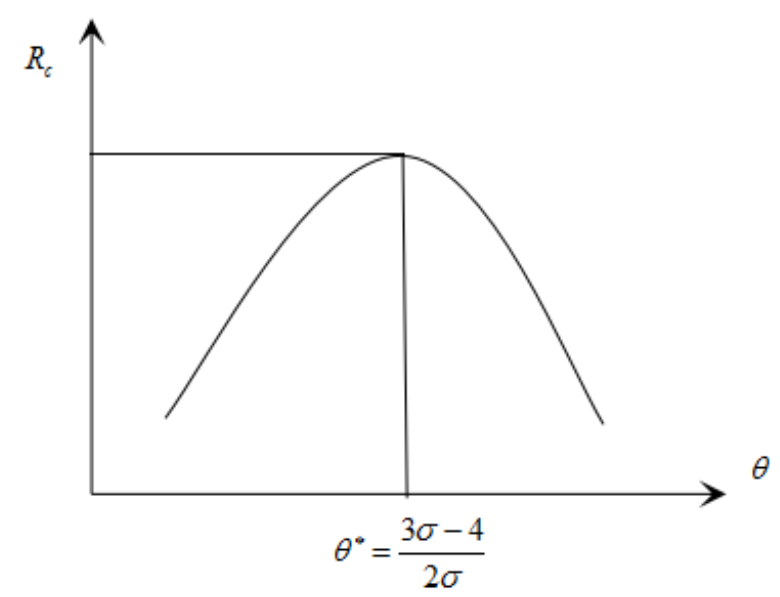

Figure 1. The relationship between intellectual property protection and technological innovation 


\section{Conclusions}

Based on the theoretical perspective, this paper examines the relationship between intellectual property protection and technological innovation in developing countries or regions. The theoretical analysis shows that when the level of intellectual property protection in developing countries is higher than a certain threshold, the level of technological innovation decreases with the strengthening of intellectual property protection. When the level of intellectual property protection is lower than a certain threshold, The level of technological innovation will increase with the strengthening of intellectual property protection.

Therefore, in order to make a country's technological innovation ability to achieve the best, there is a moderate level of intellectual property protection. This means that in order to enhance their technical capacity, intellectual property protection is too tight or too loose is not appropriate, should be based on their own technical capacity to develop appropriate intellectual property protection efforts.

\section{References}

[1] Fu X. and Yang Q., Exploring the Cross-Country Gap in Patenting: A Stochastic Frontier Approach[J], Research Policy, 2009,38(7), p1203-1213.

[2] Arrow K J., Economic Welfare and the Allocation of Resources for Invention[M], Princeton University Press, 1962.

[3] Helpman E., Innovation, Imitation, and Intellectual Property Rights[J], Ecometrica, 1993,61(6), p1247-1280.

[4] Lai E., International Intellectual Property Rights Protection and the Rate of Production Innovation[J], Journal of Development Economics, 1998,55(1), p133-153.

[5] Krammer S., Drivers of National Innovation in Transition: Evidence from a Panel of Eastern European Countries[J], Research Policy, 2009,38(5), p845-860.

[6] Lo S., Strengthening Intellectual Property Rights: Experience from the 1986 Taiwanese Patent Reforms[J], International Journal of Industrial Organization, 2011,29(5), p524-536.

[7] Kim Y., Appropriate Intellectual Property Protection and Economic Growth in Countries at Different Levels of Development[J], Research Policy, 2012,41(5), p358-375.

[8] Schneider P., International Trade, Economic Growth and Intellectual property Rights: A panel Data Study of Developed and Developing Countries[J], Journal of Development Economics, 2005,78(2), p529-547.

[9] Allred B. and Park W., Patent Rights Innovative Activity: Evidence from National and Firm-Level data[J], Journal of International Business Studies, 2007,38(6), p878-900.

[10]Hu M. and Mathews J., China's National Innovative Capacity[J], Research Policy, 2008,37(9), p1465-1479. 